\title{
The Utility and Limitations of FRAX: A US Perspective
}

\author{
Stuart L. Silverman • Andrew D. Calderon
}

Published online: 2 September 2010

(C) The Author(s) 2010. This article is published with open access at Springerlink.com

\begin{abstract}
The FRAX calculator is a major achievement in terms of our understanding of measuring fracture risk. Along with being an easily accessible web-based tool, it is the only model based on extensive data on multiple cohorts. FRAX will help clinicians identify individuals who need osteoporosis treatments, while also screening out those who do not require osteoporosis treatments. However, FRAX is limited by a number of factors. Although it is web based, few physicians have the means to access it. It also assumes that body mass index and mortality are constant across different racial and ethnic groups. FRAX is further limited by the exclusion of variables known to be associated with fracture risk, lack of dose-response relationships for variables, increased subsequent fracture risk after initial fracture, restriction to only one bone mineral density site, racial and ethnic differences that may influence fracture risk, and availability of racial and ethnic fracture risk data to be used in the FRAX calculator. Finally, the values obtained from FRAX should not take the place of good clinical judgment.
\end{abstract}

Keywords Osteoporosis · FRAX · Fracture risk · Fracture

$\begin{array}{ll}\text { Clinical Trial Acronyms } \\ \text { CaMos } & \text { Canadian Multicentre Osteoporosis Study } \\ \text { EPIDOS } & \text { Epidémiologie de l'Ostéoporose } \\ \text { EPOS } & \text { European Prospective Osteoporosis Study } \\ \text { EVOS } & \text { European Vertebral Osteoporosis Study } \\ \text { NHANES } & \begin{array}{l}\text { National Health and Nutrition Examination } \\ \text { Survey }\end{array} \\ \text { OFELY } & \begin{array}{l}\text { Os des Femmes de Lyon } \\ \end{array}\end{array}$

S. L. Silverman $(\bowtie) \cdot$ A. D. Calderon

8641 Wilshire Boulevard, Suite 301,

Beverly Hills, CA 90211, USA

e-mail: stuarts@omcresearch.org

\section{Introduction}

Despite a diverse therapeutic menu and the availability of dual-energy x-ray absorptiometry, many patients at risk for osteoporotic fracture are undiagnosed and untreated [1-4]. Bone mineral density (BMD) assessment, although specific, may not be sensitive for predicting fracture risk. Adding clinical risk factors that are able to predict fracture independent of BMD [5-8] may improve our ability to predict fracture risk.

To improve patient assessment at the primary care level, a World Health Organization (WHO) task force developed an algorithm that calculates absolute fracture risk based on population-based cohorts from Europe, North America, Asia, and Australia. The algorithm includes the following risk factors: age [9], prior fracture [10॰], parental history of hip fracture $[11 \bullet]$, low body weight or body mass index (BMI) [12], use of glucocorticoids of $5 \mathrm{mg}$ or more for 3 months or more [13•], rheumatoid arthritis (RA) [14], current cigarette smoking [15], excessive alcohol intake of 3 units or more daily ( 3 medium glasses of wine or 3 half pints of beer) [16•], and secondary osteoporosis [14]. This tool, called the FRAX tool, calculates the 10-year absolute fracture risk in individual patients for hip fractures or major osteoporotic fractures (hip, wrist, humerus, and clinical spine) [17, 18].

Earlier guidelines such as the National Osteoporosis Foundation (NOF) selected patients for treatment who had pre-existing hip or spine fracture, or low BMD with clinical risk factors. These clinical risk factors were not weighted, and patients with more than one risk factor were weighted no differently $[19,20]$. The use by WHO of combined data from multiple cohorts with different clinical risk factors has improved our ability to predict the absolute risk of fracture. The absolute risk of fracture refers to the individual risk of fractures over a certain time period [14]. Ten years was 
chosen because this was a time frame that was cost effective in modeling and allowed 5 years on and 5 years off medications [9].

We had historically defined osteoporosis by bone density alone, with osteoporosis being a T-score of 2.5 SDs below peak BMD in female populations and osteopenia, which we would now term low bone mass, between -1 and -2.5 [2124]. With the increased recognition that over half of individuals in the community with fractures do not have osteoporosis as defined by BMD, we now separate patients with low bone mass into those with low risk versus high risk. Risk factors in the WHO algorithm are required to be simple, responsive to therapies available, and have been studied in population cohorts [25].

\section{How Was FRAX Developed?}

The WHO task force first reviewed the literature using metaanalysis to identify risk factors for fracture independent of BMD. Secondly, a mega-analysis was done by combining data from 12 cohorts around the world, including studies in Australia [26, 27], Hiroshima [28, 29], multiple studies in Europe such as EVOS/EPOS [30-32], EPIDOS [33], Gothenburg I [34, 35] and II [36], Rotterdam [7], Sheffield [37], Kuopio in Finland [38], the OFELY study in France [8, 39], as well as CaMos in Canada [40] and Rochester in the United States [41, 42].

The global cohort consisted of approximately 250,000 person years, approximately 60,000 patients, and 5000 fractures. Using this analysis, the eight candidate risk factors were proposed. To be considered, each of these risk factors needed to be validated in multiple populations, adjustable for age, sex, and type of fracture, intuitive, amenable to therapeutic manipulation, and readily accessible for primary care practitioner [18, 25, 43]. Thus, factors such as calcium deficiency and risk of falling or vitamin D levels, which would not be easy for primary care physicians to measure, were not included. The clinical risk factors may be added, but the sum varies depending on the risk factors added because of differing weights. The risk factors improve prediction of fracture risk by improving the gradient of risk [44••]. The addition of clinical risk factors is most valuable for younger women and least valuable for those who are elderly. For each country we add country-specific fracture incidence rates.

In this model, we use 10-year probability of fracture not relative risk, because relative risk decreases with age. For example, by 80 years of age, the relative risk of fracture compared with other 80-year-old women with a T-score of -2.5 is reduced because many women this age are at a high risk for fracture independent of BMD. Similarly, lifetime fracture risk is not used because it begins to decline at 70 years of age because of competing risk of death.
The risk of different clinical fractures is also combined in this model, not by simply adding them but by weighting the clinical fracture based on morbidity and mortality using utility measurement compared with the utility of a so-called "hip fracture," reducing fracture risk to a common currency [45].

\section{Assumptions About FRAX}

The FRAX model requires certain assumptions that are used in the development of new country-specific models: 1) The relationship between BMI and mortality is constant across different racial and ethnic groups. 2) In many countries, we may have data on the incidence of hip fracture but no data on nonvertebral fracture and vertebral fractures. Data on these fractures are estimated based on the incidence of hip fracture using US Caucasians as the reference from the NHANES. However, this ratio may not apply across all racial and ethnic groups in countries and regions of the world.

\section{Validation of FRAX}

The FRAX model has been validated in 11 cohorts [25]. No randomized controlled trial data focusing on prevention of fractures in patients who were included based on FRAX are available. However, in post hoc analysis of intervention studies with clodronate [46] and bazedoxifene [47, 48], antifracture efficacy has been shown in patients selected high risk according to FRAX but not low risk. However, such results were not found in the post hoc analysis of raloxifene studies [49]. Further studies will be needed to evaluate the ability of treatment to reduce fracture risk in subjects at high risk for fractures based on FRAX in the absence of a prevalent fracture or fracture with BMD.

\section{When Not to Use FRAX}

FRAX does not replace good clinical judgment by the health care practitioner. For example, in patients with multiple fractures, it is anticipated the clinician would increase his or her estimate of fracture risk. Similarly, the clinician should use judgement for individuals based on corticosteroid dose and duration, multiple secondary osteoporosis risk factors, or amount of smoking and alcohol use. FRAX should not be used in individuals currently taking osteoporosis therapy.

\section{Use of Interventional Thresholds}

How do we set interventional thresholds based on FRAX? There are two possible ways. In the United States, we use 
health economics in combination with thresholds [21, 23, 50]. We continue to state that patients with a T-score of less than -2.5 in the hip or spine have osteoporosis but also ask the patients who are osteopenic or low bone mass whether they are at high risk or low risk based on FRAX, where we stated that $3 \%$ risk of hip fracture is high risk and $20 \%$ risk of major osteoporotic fracture is high risk [21, 23, 50]. In other countries, FRAX is used alone to estimate risk independent of any given BMD threshold.

\section{Strengths of FRAX}

FRAX is a major achievement in terms of our understanding of measuring fracture risk. It is the only model based on extensive data on multiple cohorts with and without BMD that has been validated in additional cohorts [17]. FRAX will help clinicians identify individuals who need osteoporosis treatment and also individuals who do not need osteoporosis treatment. FRAX is now widely accepted in treatment decisions such as the NOF guidelines. The probability of fracture can now be estimated based on clinical risk factors and BMD globally. The model uses primary data to use weighted clinical risk facture and is calibrated to local epidemiology of fracture and mortality [18]. It is now available worldwide in Asia, in China, Hong Kong, Japan, South Korea, Taiwan, and Lebanon; in Europe in Austria, Belgium, Finland, France, Germany, Hungary, The Netherlands, Italy, Spain, Sweden, Switzerland, Turkey, and the United Kingdom; in North America in the United States; in Latin America in Argentina, Columbia, and Mexico; and in Oceania in Australia and New Zealand. It is available in 11 languages.

FRAX may be useful as inclusion criteria in designing future clinical trials in which fracture is an outcome. It is important to note that background risk of fracture in FRAX will vary between populations. Therefore, it is important to calculate population-specific individualized FRAX risk and develop country-specific models. FRAX can be used dynamically over time in patients whose clinical risk factors change over time.

\section{Limitations of FRAX}

FRAX has multiple limitations:

1. Certain variables were excluded. For example, FRAX does not include measurements that would be difficult to obtain by a primary care practitioner-measurements of physical activity, vitamin D deficiency, bone turnover markers, or loss of bone mass between sequential BMD measurements $[17,18]$. For example, falls were explicitly excluded. Reasons given are about lack of standardized evaluation methods, the lack of data showing fall prevention measures, and decreased risk of fractures. However, we do clearly recognize falls as a risk for fractures independently of bone-related risk for nonvertebral fractures including hip fractures.

2. FRAX does not take into account dose-response relationships. For example, FRAX does not make a difference between single versus multiple fractures, different doses and duration of glucocorticoid use, and different doses of units and duration of use of alcohol or smoking in terms of packs per day. It does not take into account characteristics for prior fractures such as number, severity, and type $[17,18,51]$.

3. The increased subsequent fracture risk after initial fracture is considered constant over time in FRAX. However, observational studies have shown that subsequent fracture risk fluctuates over time and may be highest in the first 5 years after initial fracture [25].

4. FRAX may only be used in untreated patients $[19,20]$.

5. The BMD input is limited to the femoral neck based on available population data. FRAX does not account for individuals who have low lumbar T-score but with normal femoral neck [19].

6. Patient ascertainment of RA. Individuals may think they have RA when it really is osteoarthritis [25].

7. Poor definition of secondary osteoporosis. The current model assumes that the additional risk of secondary osteoporosis is mediated largely through BMD. If BMD is entered, secondary osteoporosis does not change the calculated risk. Furthermore, multiple risk factors account for secondary osteoporosis. FRAX does not take into account combinations of multiple risks such as hypothyroidism and malabsorption due to gastric bypass [51].

8. Internet access. Not all physicians have Internet access in their examination rooms at this time [25, 43].

9. Relationship between BMI and mortality. FRAX assumes that the relationship between BMI and mortality in all races and ethnic groups are similar. There are no data to know if this is true for African Americans, Hispanics, and Asians [52].

10. There may be racial or ethnic differences that influence fracture risk not taken into account by FRAX. When BMD is absent, fracture risk in Hispanics and African Americans appears to be underestimated [52].

11. Variability in fracture rates. FRAX assumes that the variability in fracture rates is similar across race and ethnic groups in the United States. The variability in hip fracture rates in Hispanics is greater than in Caucasians in the United States [52]. 


\section{Future Uses of FRAX}

FRAX may be used for randomized control trials as inclusion criteria for following fracture risk over time.

\section{Alternatives of FRAX}

Do we need all the clinical risk factors in FRAX? Cummings and Melton [53] bring out in recent papers that there are several strong factors, as do Black et al. [54], that may well account for most of fracture risk such as BMD or BMI, age, and past medical history of fracture. Several alternatives of FRAX exist such as the Canadian Osteoporosis Society [55], the Nguyen algorithm [56], and the Dutch algorithm [57]. These risk factor algorithms depend on a smaller number of clinical risk factors. They are often only valid and include other additional factors that may not be included in FRAX such as falls. They are often validated only in a given observational study or given cohort and at this time may not have generalized applicability. They need to be validated in different countries.

\section{Statistical Literacy}

Communication about FRAX risk depends on the patient's understanding of the statistical concept of risk, which has been called statistical numeracy [58]. Statistical numeracy is essential if our patients are to understand health-related risks and make informed medical decisions. Statistical numeracy is part of a more general concept of qualitative and quantitative mathematical literacy.

In a recent study by Galesic et al. [58] using a numeracy scale, a large gap was identified in the United States between patients with lower and higher educational levels. Although a college-educated American could answer $83 \%$ correctly, those with less than high school education could only answer $40 \%$. For example, $20 \%$ of US participants could not say which of the following numbers represented the biggest risk of disease: $1 \%, 5 \%$, or $10 \%$, and about $76.5 \%$ of US participants could not transform 1 in 1000 to a percentage. Even physicians had difficulty, with $25 \%$ of physicians unable to correctly convert this into a percentage.

\section{Impact of FRAX Information}

It is likely that the advent of FRAX will result in minimal change in treatment of women with osteoporosis as defined by fracture or low T-score. However, it is very likely women with low bone mass and low risk will be less likely to be treated. We can hypothesize those younger women who are told they have osteopenia but are at low risk for major osteoporotic fracture would not be willing to take a medicine that would then reduce their risk by a half. In one study by Ettinger et al. [59], physicians who are shown clinical data and information on absolute risk are less likely to prescribe medication than when shown only clinical data.

There have been no studies as yet to confirm whether the use of FRAX will improve outcomes. If we look at risk estimation in other disease states such as coronary heart disease (CHD), we see that global risk estimation for coronary artery disease calculated by combining risk factors along with accompanying education increased the accuracy of perceived risk and increased intent to start therapy. This intervention reduced predicted CHD by $-0.2 \%$ to $2 \%$ over 10 years when given repeatedly over time. Therefore, it is likely that providing global risk information to patients at only one point in time may well be relatively ineffective [60]. We should thus consider repeating FRAX information over time. The effect on FRAX on distal outcomes is less clear. It may depend on the intensity of accompanying interventions.

FRAX has recently been added to bone density software. It is currently on a calculator in Japan, a CD in Poland, and has now appeared on the US iPhone. The FRAX website has about 60,000 hits daily, with total cumulative hits of about

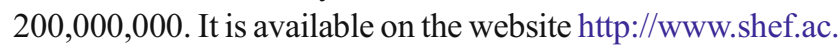
uk, and also now on PDA and simple paper-based models on a FRAX calculator through the International Osteoporosis Foundation.

\section{Conclusions}

The FRAX calculator is a major tool for identifying patients who may need osteoporosis treatments as well as identifying patients who may not need osteoporosis treatments. Although FRAX has utility as a clinical tool, it also has multiple limitations that may affect fracture risk calculations. Despite these limitations, FRAX is being used globally by physicians to assess fracture risk. The use of FRAX, although currently limited, will increase once incorporated into BMD software and PDAs.

Disclosure Dr. Stuart Silverman has received grants from Eli Lilly and Co., and Alliance for Better Bone Health. He has received honoraria from Eli Lilly, Roche Pharmaceuticals, and Pfizer. And he has consulted for Warner Chilcott, Roche Pharmaceuticals, Roche Diagnostics, Novartis, Pfizer, and Eli Lilly and Co. 
Open Access This article is distributed under the terms of the Creative Commons Attribution Noncommercial License which permits any noncommercial use, distribution, and reproduction in any medium, provided the original author(s) and source are credited.

\section{References}

Papers of particular interest, published recently, have been highlighted as:

- Of importance

- Of major importance

1. Nguyen TV, Center JR, Eisman JA: Osteoporosis: underrated, underdiagnosed and undertreated. Med J Aust 2004, 180:S18-S22.

2. Delmas PD, van de Langerijt L, Watts NB, et al.: Underdiagnosis of vertebral fractures is a worldwide problem: the IMPACT study. J Bone Miner Res 2005, 20:557-563.

3. Vestergaard P, Rejnmark L, Mosekilde L: Osteoporosis is markedly underdiagnosed: a nationwide study from Denmark. Osteoporos Int 2005, 16:134-141.

4. Iba K, Takada J, Hatakeyama N, et al.: Underutilization of antiosteoporotic drugs by orthopedic surgeons for prevention of a secondary osteoporotic fracture. J Orthop Sci 2006, 11:446-449.

5. Siris ES, Chen YT, Abbott TA, et al.: Bone mineral density thresholds for pharmacological intervention to prevent fractures. Arch Intern Med 2004, 164:1108-1112.

6. Wainwright SA, Marshall LM, Ensrud KE, et al.: Hip fracture in women without osteoporosis. J Clin Endocrinol Metab 2005, 90:2787-2793.

7. van der Klift M, de Laet CE, McCloskey EV, et al.: Risk factors for incident vertebral fractures in men and women: the Rotterdam Study. J Bone Miner Res 2004, 19:1172-1180.

8. Sornay-Rendu E, Munoz F, Garnero P, et al.: Identification of osteopenic women at high risk of fracture: the OFELY Study. J Bone Miner Res 2005, 20:1813-1819.

9. Kanis JA, Johnell O, Oden A, et al.: Ten year probabilities of osteoporotic fractures according to BMD and diagnostic thresholds. Osteoporos Int 2001, 12:989-995.

10. • Kanis JA, Johnell O, De Laet C, et al.: A meta-analysis of previous fracture and subsequent fracture risk. Bone 2004, 35:375-382. This paper demonstrates the importance of a history of previous fracture as a risk factor for fracture independent of BMD.

11. - Kanis JA, Johansson H, Oden A, et al.: A family history of fracture and fracture risk: a meta-analysis. Bone 2004, 35:1029 1037. This paper demonstrates the importance of family history of fracture as a risk factor for fracture independent of BMD.

12. De Laet C, Kanis JA, Oden A, et al.: Body mass index as a predictor of fracture risk: a meta-analysis. Osteoporos Int 2005, 16:1330-1338.

13. - Kanis JA, Johansson H, Oden A, et al.: A meta-analysis of prior corticosteroid use and fracture risk. J Bone Miner Res 2004, 19:893-899. This paper demonstrates the importance of prior corticosteroid use as a risk factor for fracture independent of $B M D$.

14. Kanis JA, Borgstrom F, De Laet C, et al.: Assessment of fracture risk. Osteoporos Int 2005, 16:581-589.

15. Kanis JA, Johnell O, Oden A, et al.: Smoking and fracture risk: a meta-analysis. Osteoporos Int 2005, 16:155-162.

16. - Kanis JA, Johansson H, Johnell O, et al.: Alcohol intake as a risk factor for fracture. Osteoporos Int 2005, 16:737-742. This paper demonstrates alcohol intake as a risk factor for fracture independent of $B M D$.
17. Kanis JA, Johnell O, Oden A, et al.: FRAX and the assessment of fracture probability in men and women from the UK. Osteoporos Int 2008, 19:385-397.

18. Kanis JA, Oden A, Johansson H, et al.: FRAX and its applications to clinical practice. Bone 2009, 44:734-743.

19. National Osteoporosis Foundation: Clinician's Guide to Prevention and Treatment of Osteoporosis. Available at http://www.nof.org/ professionals/Clinicians Guide.htm. Accessed October 28, 2009.

20. National Osteoporosis Foundation, International Society for Clinical Densitometry: National Osteoporosis Foundation (NOF)/ International Society for Clinical Densitometry (ISCD) FRAX Implementation Guide. Available at http://www.iscd.org/Visitors/pdfs/ FRAXImplementationGuide 000.pdf. Accessed November 25, 2009.

21. Lewiecki EM: Review of guidelines for bone mineral density testing and treatment of osteoporosis. Curr Osteoporos Rep 2005, 3:75-83.

22. Kanis JA, Torgerson D, Cooper C: Comparison of the European and USA practice guidelines for osteoporosis. Trends Endocrinol Metab 2000, 11:28-32.

23. Physician's Guide to Prevention and Treatment of Osteoporosis. Washington, DC: National Osteoporosis Foundation; 2003.

24. Kanis JA, Oden A, Johnell O, et al.: The use of clinical risk factors enhances the performance of BMD in the prediction of hip and osteoporotic fractures in men and women. Osteoporos Int 2007, 18:1033-1046.

25. Watts NB, Ettinger B, LeBoff MS: FRAX facts. J Bone Miner Res 2009, 76:1-3.

26. Jones G, Nguyen TV, Sambrook PN, et al.: Symptomatic fracture incidence in elderly men and women. The Dubbo Osteoporosis Epidemiology Study (DOES). Osteoporos Int 1994, 4:277-282.

27. Nguyen TV, Eisman JA, Kelly PJ, Sambrook PN: Risk factors for osteoporotic fractures in elderly men. Am J Epidemiol 1996, 144:255-263.

28. Fujiwara S, Kasagi F, Yamada M, Kodama K: Risk factors for hip fracture in Japanese cohort. J Bone Miner Res 1997, 12:998-1004.

29. Fujiwara S, Fumiyoshi K, Masunari N, et al.: Fracture prediction from bone mineral density in Japanese men and women. J Bone Miner Res 2003, 18:1547-1553.

30. O'Neill TW, Felsenberg D, Varlow J, et al.: The prevalence of vertebral deformity in European men and women: the European Vertebral Osteoporosis Study. J Bone Miner Res 1996, 11:1010 1017.

31. Felsenberg D, Silman AJ, Lunt M, et al.: Incidence of vertebral fracture in Europe: results from the European Prospective Osteoporosis Study (EPOS). J Bone Miner Res 2002, 17:716-724.

32. Ismail AA, Pye SR, Cockerill WC, et al.: Incidence of limb fracture across Europe: results from the European Prospective Osteoporosis Study (EPOS). Osteoporos Int 2002, 13:565-571.

33. Robbins JA, Schott AM, Garnero P, et al.: Risk factors for hip fracture in women with high BMD: the EPIDOS study. Osteopor Int 2005, 16:149-154.

34. Svanborg A: Seventy-year-old people in Gothenburg. A population study in an industrialized Swedish city. II. General presentation of social and medical conditions. Acta Med Scand Suppl 1977, 611:5-37.

35. Johansson C, Black D, Johnell O, et al.: Bone mineral density is a predictor of survival. Calcif Tissue Int 1998, 63:190-196.

36. Stenstrom M, Olsson JO, Mellstrom D: Thyroid hormone replacement is not related to increased risk of osteoporosis. Osteoporos Int 2000, 11(Suppl 2):S144.

37. Johansson H, Oden A, Johnell O, et al.: Optimization of BMD measurements to identify high risk groups for treatment - a test analysis. J Bone Miner Res 2004, 19:906-913.

38. Honkanen R, Kroger H, Tuppurainen M, et al.: Fractures and low axial bone density in perimenopausal women. J Clin Epidemiol $1995,48: 881-888$ 
39. Albrand G, Munoz F, Sornay-Rendu E, et al.: Independent predictors of all osteoporosis related fractures in healthy postmenopausal women: the OFELY study. Bone 2003, 32:78-85.

40. Sawka AM, Thabane L, Papaioannou A, et al.: Health-related quality of life measurements in elderly Canadians with osteoporosis compared to other chronic medical conditions: a population-based study from the Canadian Multicentre Osteoporosis Study (CaMos). Osteoporos Int 2005, 16:1836-1840.

41. Melton LJ 3 rd, Crowson CS, O'Fallon WM, et al.: Relative contributions of bone density, bone turnover and clinical risk factors to long-term fracture prediction. J Bone Miner Res 2003, 18:312-318.

42. Melton LJ 3 rd, Atkinson EJ, O'Connor MK, et al.: Bone density and fracture risk in men. J Bone Miner Res 1998, 13:1915-1923.

43. Nanes MS, Kallen CB: Clinical assessment of fracture risk and novel therapeutic strategies to combat osteoporosis. Fertil Steril 2009, 92:403-412.

44. •• De Laet C, Oden A, Johansson H, et al.: The impact of the use of multiple risk indicators for fracture on case-finding strategies: a mathematical approach. Osteoporos Int 2005, 16:313-318. This paper explains how multiple risk factors can be integrated to improve the prediction of fracture risk.

45. Ettinger B: A personal perspective on fracture risk assessment tools. Menopause 2008, 15:1023-1026.

46. McCloskey EV, Johansson H, Oden A, et al.: Ten-year fracture probability identifies women who will benefit from clodronate therapy-additional results from a double-blind, placebocontrolled randomized study. Osteoporos Int 2009, 20:811-817.

47. Kanis JA, Johansson H, Oden A, McCloskey EV: Bazedoxifene reduces vertebral and clinical fractures in postmenopausal women at high risk assessed with FRAX. Bone 2009, 22:1049-1054.

48. McCloskey E, Johansson H, Oden A, et al.: Assessment of the effect of bazedoxifene on non-vertebral fracture risk. J Bone Miner Res 24 (Suppl 1). Available at http://www.asbmr.org/ Meetings/AnnualMeeting/AbstractDetail.aspx?aid=6c55b263692e-4a37-b807-f7a153641564. Accessed August 2010.

49. Ettinger B, Black Dm, Mitlak BH, et al.: Reduction in vertebral fracture risk in postmenopausal women with osteoporosis with raloxifene: results from a 3 year randomized clinical trial. Multiple
Outcomes of Raloxifene Evaluation (MORE) investigators. JAMA 1999, 282:637-645.

50. Kanis JA, Johnell O, Oden A, et al.: Intervention thresholds for osteoporosis in men and women: a study based on data from Sweden. Osteoporos Int 2005, 16:6-14.

51. Lewiecki EM, Watts NB: New guidelines for the prevention and treatment of osteoporosis. South Med J 2009, 102:175-179.

52. Kanis JA on behalf of the World Health Organization Scientific group: Assessment of Osteoporosis at the Primary Health-Care Level. Technical Report. Sheffield, UK: Edited by the World Health Organization Collaborating Centre for Metabolic Bone Diseases. Printed by the University of Sheffield; 2007.

53. Cummings S, Melton L: Epidemiology and outcomes of osteoporotic fractures. Lancet 2002, 359:1761-1767.

54. Black DL, Dalziel R, Young D, Shimmin A: Early results of primary Birmingham hip resurfacings: an independent prospective study of the first 230 hips. J Bone Joint Surg Br 2005, 87:324-329.

55. Brown JP, Josse RG; Scientific Advisory Council of the Osteoporosis Society of Canada: 2002 clinical practice guidelines for the diagnosis and management of osteoporosis in Canada. CMAJ 2002, 167(10 Suppl):S1-S34.

56. Pluskiewicz W, Adamczy KP, Franek E, et al.: Ten-year probability of osteoporotic fracture in 2012 Polish women assessed by FRAX and nomogram by Nguyen et al.- Conformity between methods and their clinical utility. Bone 2010, 46:1661-1667.

57. Plumijm S, Koes B, de Laet C, et al. : A simple risk score for the assessment of absolute fracture risk in general practice based on two longitudinal studies. J Bone Miner Res 2009, 24:768-774.

58. Galesic M, Garcia-Retamero R: Statistical numeracy for health: a cross-cultural comparison with probabilistic national samples. Arch Intern Med 2010, 170:462-468.

59. Ettinger B, Hillier TA, Pressman A, et al.: Simple computer model for calculating and reporting 5-year osteoporotic fracture risk in postmenopausal women. J Womens Health (Larchmt) 2005, 14:159-171.

60. Sheridan SL, Viera AJ, Krantz MJ, et al.; the Cardiovascular Health Intervention Research and Translation Network Work Group on Global Coronary Heart Disease Risk: The effect of giving global coronary risk information to adults: a systematic review. Arch Intern Med 2010, 170:230-239. 